\title{
Ionization and transfection activity of n-methyl-substituted carbamoyl-cholesterol derivatives
}

\author{
Samuel Acheampong, Michalakis Savva* \\ Division of pharmaceuticals Sciences, Arnold \& Marie Schwartz College of Pharmacy and Health Sciences, Long Island University, \\ New York, USA; *Corresponding Author: micsavva@gmail.com
}

Received 10 November 2010; revised 13 December 2010; accepted 29 December 2010.

\begin{abstract}
Five novel cationic lipids, the polar head group of which was attached to the cholesterol backbone via a tertiary carbamate linker, were synthesized and their physicochemical properties were compared to their transfection efficiencies. Transfection activity of the primary amine analog was highest among the series, while the quaternary ammonium iodide salt was essentially transfection incompetent. Contrary to DC-Chol, methyl and ethyl carbamoyl derivatives of DCChol mediated high levels of transfection in the absence of DOPE. Ionization of the cationic assemblies in $40 \mathrm{mM}$ Tris buffer pH 7.2 exactly correlated with the competitive nature of the inductive and steric effects of the methyl groups on the aliphatic nitrogen of the lipids' polar moiety. Interestingly, the $\mathrm{pH}$ interaction zone of all lipid dispersions at $25^{\circ} \mathrm{C}$ was extended by \pm 2 $\mathrm{pH}$ units from the pKa, while the pKa of the cationic lipids determined in mixed vesicles composed of $90 \%$ DOPC and cholesterol was approximately 1.3 to 1.5 times higher than that of pure cationic assemblies. The interaction of cationic lipids with plasmid DNA was correlated with pKa, but not the transfection activity.
\end{abstract}

Keywords: Cationic Lipids; DC-Chol; Transfection; Pka; Plasmid DNA; Monolayer; Surface Pressure

\section{INTRODUCTION}

Cholesterol-based cationic lipids are one of the most promising series of reagents for in vitro and in vivo gene delivery [1-4]. Over the years, these structures were systematically varied in an effort to generate structureactivity relationships to rationalize their design and effectively optimize their transfection efficiency [5-8]. Most of the approaches focus on attaching a hydrophilic basic moiety capable of binding to the negatively char- ged nucleic acid, to the membrane compatible cholesterol moiety via a chemical linker. Quite frequently, the polar head group of these lipids is composed of a primary, secondary, tertiary or quaternary amine and almost always these lipids require the presence of the helper lipid DOPE in order to mediate transfection. DOPE is a zwitterionic amphiphil that forms reverse hexagonal phases $\left(\mathrm{H}_{\mathrm{II}}\right)$ at physiological $\mathrm{pH}$ and is widely believed to promote fusion with cell membranes, facilitate endosomal escape, reduce the toxicity and increase the transfection activity of lipoplexes [9-13].

In our recent report, the physicochemical properties of cholesterol-based cationic lipids carrying a secondary carbamate linker were correlated with their transfection activity in the absence of helper lipids. The study found that the tertiary and quaternary amine derivatives, DCChol and TC-Chol (herein termed DC and TC), failed to mediate transfection and further concluded that the high transfection activity mediated by the primary and secondary analogs $\mathrm{AC}$ and $\mathrm{MC}$ in the absence of DOPE, was due to their increased association with plasma membrane and endosomal escape [14]. The aim of this investigation was to examine how methylation on the carbamoyl nitrogen affects the lipids' ionization, interaction with plasmid DNA and transfection activity.

\section{MATERIAL AND METHODS}

$\mathrm{N}$-methylethylenediamine $95 \%$, N,N'-dimethylethylenediamine $99 \%$, N,N,N'-trimethylethylene-diamine $97 \%$, N,N-dimethyl-N'-ethylethylenediamine $98 \%$, Cholesteryl chloroformate $97 \%$, iodomethane $99.5 \%$, 2-hydroxyethylmercaptan, 3-(4,5-dimethylthiazol-2-yl)-2,5-diphenyltetrazolium bromide (MTT) and $o$-nitrophenyl- $\beta$-Dgalactopyranoside (ONPG) were purchased from SigmaAldrich (St. Louis, MO). Tris-(hydroxymethyl)-aminomethane (ultrapure grade) and edetate disodium dihydrate (EDTA) were purchased from Spectrum Chemical Manufacturing Company (New Brunswick, NJ). Murine melanoma cells B16F0 and Dulbecco's modified 


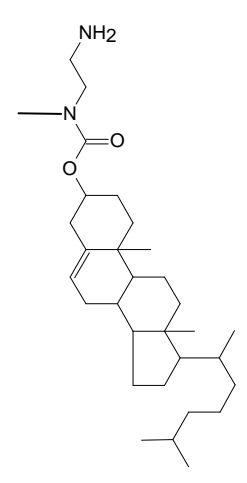

MAC

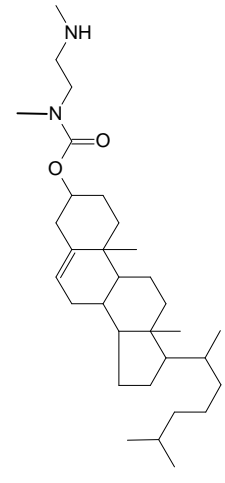

MMC

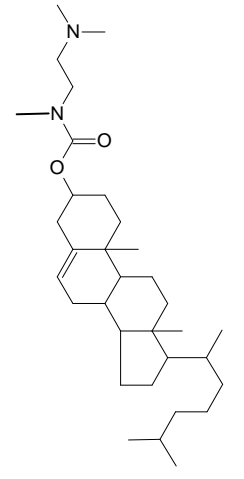

MDC

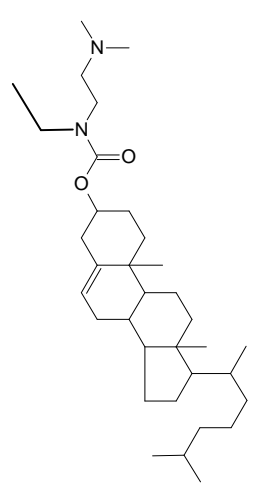

EDC

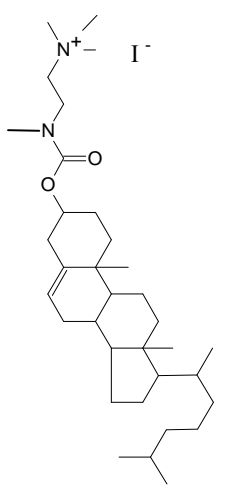

MTC

Scheme 1. Cholesterol-based cationic lipids.

Eagle's medium (DMEM) were obtained from American Type Culture Collection (Manassas, VA). Fetal calf serum, penicillin (5 000 units)/streptomycin $(5,000 \mu \mathrm{g})$ and ethidium bromide solution $\left(10 \mathrm{mg} \cdot \mathrm{mL}^{-1}\right)$ were obtained from Invitrogen Corporation (Grand Island, NY). 1,2dioleoyl-sn-glycero-3-phosphatidylcholine (DOPC) was purchased from Avanti Polar Lipids, Inc. (Alabaster, AL).

\subsection{Synthesis}

The cholesterol-based analogues MAC, MMC, MDC and EDC (Scheme 1) were synthesized from N-methylethylenediamine, N,N'-dimethylethylenediamine, N,N,N'trimethylethylene-diamine and N,N-dimethyl-N'-ethylethylenediamine, respectively, at yields $>75 \%$, as described elsewhere [14]. The quaternary ammonium derivative MTC was synthesized by refluxing MDC in the presence of an equimolar concentration of methyl iodide for $2 \mathrm{~h}$.

\section{3 $\beta$-[2-(aminoethyl)-methylcarbamoyl]- cholesterol (MAC)}

Anal. Calcd for $\mathrm{C}_{31} \mathrm{H}_{54} \mathrm{~N}_{2} \mathrm{O}_{2}$ (MW 486.42): C, 76.42; H, 11.09; N, 5.75, Found: C, 75.44; H, 11.09; N, 5.68, MS (Positive/Negative ES) $\mathrm{m} / \mathrm{z} \quad 487.43 \quad[\mathrm{M}+\mathrm{H}]^{+} ;{ }^{1} \mathrm{H}$ NMR (400 MHz, $\left.\mathrm{CdCl}_{3}, 20^{\circ} \mathrm{C}, \mathrm{TMS}\right) \delta 0.68(\mathrm{~s}, 3 \mathrm{H}$, H'18), 0.85 - 0.88 (d, 6H, H'26 - H'27), 0.90 - 0.92 (d, 3H, H'21), 1.02 (s, 3H, H'19), 1.04 - 1.59 (m, 21H, H'1, H'9, H'11 - H'12, H'14 - H'17, H'20, H'22 - H'25), 1.81 - 2.02 (m, 5H, H'2, H'7, H'8), 2.30 - 2.35 (m, 2H, H'4), 2.83 - $2.94\left(\mathrm{~m}, 5 \mathrm{H}, \mathrm{H}_{2} \mathrm{NCH}_{2}, \mathrm{OCON}\left(\mathrm{CH}_{3}\right) \mathrm{CH}_{2}\right), 3.31$ $3.32\left(\mathrm{~m}, 2 \mathrm{H}, \mathrm{OCON}\left(\mathrm{CH}_{3}\right) \mathrm{CH}_{2}\right), 4.53\left(\mathrm{~m}, 1 \mathrm{H}, \mathrm{H}^{\prime} 3\right), 5.37$ - $5.38\left(\mathrm{~d}, 1 \mathrm{H}, J=5, \mathrm{H}^{\prime} 6\right)$.

\section{3 $\beta$-[[2-(methylamino)ethyl]-methylcarbamoyl]- cholesterol (MMC)}

Anal. Calcd for $\mathrm{C}_{32} \mathrm{H}_{56} \mathrm{~N}_{2} \mathrm{O}_{2}$ (MW 500.4): C, 76.68; $\mathrm{H}$, 11.18; N, 5.59, Found: C, 75.34; H, 11.04; N, 5.49, MS
(Positive/Negative ES) m/z 501.3 [M $+\mathrm{H}]^{+} ;{ }^{1} \mathrm{H}$ NMR (400 MHz, $\mathrm{CdCl}_{3}, 20^{\circ} \mathrm{C}$, TMS) $\delta 0.67$ (s, 3H, H'18), 0.85 - 0.88 (d, 6H, H'26-H'27), 0.90 - 0.92 (d, 3H, H'21), 1.02 (s, 3H, H'19), 1.04 - 1.63 (m, 21H, H'1, H'9, H'11 H'12, H'14 - H'17, H'20, H'22 - H'25), 1.78 - 2.02 (m, 5H, H'2, H'7, H'8), 2.26 - 2.38 (m, 2H, H'4), 2.46 (s, 3H, $\left.\mathrm{NH}\left(\mathrm{CH}_{3}\right)\right), 2.74\left(\mathrm{~m}, 2 \mathrm{H},\left(\mathrm{CH}_{3}\right) \mathrm{HNCH}_{2}\right), 2.93(\mathrm{~s}, 3 \mathrm{H}$, $\left.\operatorname{OCON}\left(\mathrm{CH}_{3}\right) \mathrm{CH}_{2}\right), 3.38\left(\mathrm{~m}, 2 \mathrm{H}, \mathrm{OCON}\left(\mathrm{CH}_{3}\right) \mathrm{CH}_{2}\right), 4.51$ (m, 1H, H’3), 5.37 - 5.38 (d, 1H, $\left.J=5, \mathrm{H}^{\prime} 6\right)$.

\section{3ß-[[2-(dimethylamino)ethyl]-methylcarbamoyl]- cholesterol (MDC)}

Anal. Calcd for $\mathrm{C}_{33} \mathrm{H}_{58} \mathrm{~N}_{2} \mathrm{O}_{2}$ (MW 514.4): C, 76.92; H, 11.27; N, 5.44, Found: C, 76.93; H, 11.64; N, 5.33, MS (Positive/Negative ES) m/z 515.3 [M $+\mathrm{H}]^{+} ;{ }^{1} \mathrm{H}$ NMR (400 MHz, $\mathrm{CdCl}_{3}, 20^{\circ} \mathrm{C}$, TMS) $\delta 0.63$ (s, 3H, H'18), 0.82 - 0.84 (d, 6H, H'26 - H'27), 0.87 - 0.90 (d, 3H, H'21), 0.97 (s, 3H, H'19), 1.00-1.60 (m, 21H, H'1, H'9, H'11H'12, H'14 - H'17, H'20, H'22 - H'25), 1.75 - 1.98 (m, $\left.5 \mathrm{H}, \mathrm{H}^{\prime} 2, \mathrm{H}^{\prime} 7, \mathrm{H}^{\prime} 8\right), 2.22$ (s, 6H, N($\left.\left(\mathrm{CH}_{3}\right)_{2}\right), 2.36-2.40$ $\left(\mathrm{m}, 4 \mathrm{H}, \mathrm{H}^{\prime} 4,\left(\mathrm{CH}_{3}\right)_{2} \mathrm{NCH}_{2}\right), 2.87\left(\mathrm{~s}, 3 \mathrm{H}, \mathrm{OCON}\left(\mathrm{CH}_{3}\right)\right.$ $\left.\mathrm{CH}_{2}\right), 3.20-3.36\left(\mathrm{~m}, 2 \mathrm{H}, \mathrm{OCON}\left(\mathrm{CH}_{3}\right) \mathrm{CH}_{2}\right), 4.48-4.52$ (m, 1H, H'3), 5.36 - 5.38 (d, 1H, $\left.J=5, \mathrm{H}^{\prime} 6\right)$.

\section{3 $\beta$-[[2-(dimethylamino)ethyl]-ethylcarbamoyl]- cholesterol (EDC)}

Anal. Calcd for $\mathrm{C}_{34} \mathrm{H}_{60} \mathrm{~N}_{2} \mathrm{O}_{2}$ (MW 528.5): C, 77.15; H, 11.34; N, 5.29, Found: C, 76.05; H, 11.38; N, 4.79, MS (Positive/Negative ES) m/z 529.5 [M $+\mathrm{H}]^{+} ;{ }^{1} \mathrm{H}$ NMR (400 MHz, $\mathrm{CdCl}_{3}, 20^{\circ} \mathrm{C}$, TMS) $\delta 0.63$ (s, 3H, H'18), 0.81 - 0.83 (d, 6H, H'26 - H'27), 0.86 - 0.88 (d, 3H, H'21), 0.97 (s, 3H, H'19), 1.08 - 1.58 (m, 21H, H'1, H'9, H'11 H'12, H'14 - H'17, H'20, H'22 - H'25), 1.76 - 2.00 (m, 5H, H'2, H'7, H'8), 2.20 - 2.36 (m, 2H, H'4), 2.42 (s, 6H, $\left.\mathrm{N}\left(\mathrm{CH}_{3}\right)_{2}\right), 2.70\left(\mathrm{~m}, 2 \mathrm{H},\left(\mathrm{CH}_{3}\right)_{2} \mathrm{NCH}_{2}\right), 2.91$ (bs, 5H, $\left.\operatorname{OCON}\left(\mathrm{C}_{2} \mathrm{H}_{5}\right) \mathrm{CH}_{2}\right), 3.38\left(\mathrm{~m}, 2 \mathrm{H}, \quad \mathrm{OCON}\left(\mathrm{C}_{2} \mathrm{H}_{5}\right) \mathrm{CH}_{2}\right)$, 4.48 - 4.52 (m, 1H, H'3), 5.36 - 5.38 (d, 1H, J=5, H'6). 


\section{$3 \beta$-[[2-(trimethylamino)ethyl]-methylcarbamoyl]- cholesterol iodide (MTC)}

Anal. Calcd for $\mathrm{C}_{34} \mathrm{H}_{61} \mathrm{~N}_{2} \mathrm{O}_{2} \mathrm{I}$ (MW 656.4): C, 62.16; H, 9.45; N, 4.27, Found: C, 58.19; H, 9.37; N, 4.05, MS (Positive/Negative ES) $\mathrm{m} / \mathrm{z} 529.4$ [cation of salt], ${ }^{1} \mathrm{H}$ NMR $\left(400 \mathrm{MHz}, \mathrm{CdCl}_{3}, 20^{\circ} \mathrm{C}, \mathrm{TMS}\right) \delta 0.68(\mathrm{~s}, 3 \mathrm{H}$, H'18), 0.85 - 1.74 (m, 33H, H'1, H'9, H'11 - H'12, H'14 - H'17, H'19 - H'27), 1.85 - 1.97 (m, 5H, H'2, H'7, H'8), 2.35 (m, 2H, H'4), 3.08 (bs, 3H, OCON $\left.\left(\mathrm{CH}_{3}\right) \mathrm{CH}_{2}\right), 3.50$ (s, $\left.9 \mathrm{H}, \mathrm{N}\left(\mathrm{CH}_{3}\right)_{3}\right), 3.80$ - 4.04 (m, $\left.4 \mathrm{H}, \mathrm{NCH}_{2} \mathrm{CH}_{2} \mathrm{~N}\right), 4.45$ (m, 1H, H'3), 5.40 (d, 1H, $\left.J=5, \mathrm{H}^{\prime} 6\right)$.

\subsection{Transfection and Cytotoxicity}

The studies were conducted as described elsewhere [14]. Briefly, the plasmid DNA pUC19- $\beta$-gal was propagated in DH5 $\alpha$-competent cells using standard protocols [15] and purified by gel permeation chromatography using Sepharose 4B as the stationary phase and $2.5 \mathrm{M}$ ammonium acetate as the mobile phase. Fractions containing plasmid DNA were pooled and precipitated with isopropyl alcohol. The precipitate was resuspended in a few $\mathrm{mL}$ of $40 \mathrm{mM}$ TE buffer $\mathrm{pH} 8$, dialyzed for $2-4 \mathrm{~h}$ at room temperature against $40 \mathrm{mM}$ TE buffer to eliminate traces of ammonium acetate and quantified by its absorption at $260 \mathrm{~nm}\left(4.63 \mathrm{mg} \cdot \mathrm{mL}^{-1}\right)$. The integrity and purity of the pDNA was verified by agarose gel electrophoresis and a $260 \mathrm{~nm} / 280 \mathrm{~nm}$ absorption ratio of 1.8 . B16F0 cells were cultured to confluence using DMEM supplemented with $10 \%$ fetal bovine serum, 50 units $\cdot \mathrm{mL}^{-1}$ penicillin, 50 $\mu \mathrm{g} \cdot \mathrm{mL}^{-1}$ streptomycin in a $5 \% \mathrm{CO}_{2}$ at $37^{\circ} \mathrm{C}$. Approximately 50,000 cells in $0.5 \mathrm{~mL}$ growth media were added to each well of 48 well plates. After 12 to 14 hours later, the serum media were removed and the cells were transfected with $250 \mu \mathrm{L}$ lipoplexes per well. The amount of plasmid DNA was kept constant at $1 \mu \mathrm{g}$ per well, while the amount of cationic lipid was increased appropriately to achieve cationic lipid to DNA charge ratios of $1: 1,2$ : 1 and $4: 1$. The cells were incubated for 4 hours, after which time the lipoplexes were removed and the serum free media were replaced with complete growth media. After an additional incubation of $44 \mathrm{~h}$, the cells were washed with cold phosphate-buffered saline (PBS) pH 7.4 twice and lysed with $150 \mu \mathrm{L}$ lysis buffer $(0.1 \mathrm{M}$ Tris $\mathrm{pH}$ $7.2,0.1 \% \mathrm{w} / \mathrm{v}$ Triton $\mathrm{X}$ ) per well. Beta-galactosidase activity was quantified by an ONPG assay. The cytotoxicity of cationic lipids was evaluated by an MTT assay as described elsewhere [14].

\subsection{EtBr Displacement Studies}

A Cary Eclipse spectrofluorometer was used to assess the level of displacement of ethidium bromide $(\mathrm{EtBr})$ from the pDNA (pUC19). Briefly, $0.8 \mu \mathrm{g}$ of $\mathrm{EtBr}$ and
$22.5 \mu \mathrm{g}$ of pDNA were diluted to $3 \mathrm{~mL}$ in either Tris buffer $\mathrm{pH} 7.2$ or in serum free media (SFM). Aliquots of $11.4 \mu \mathrm{l}$ of cationic lipid $(1.2 \mathrm{mM})$ were added to the solution until there was either a complete quenching of the $\mathrm{EtBr}$ or no apparent change in the fluorescence intensity. All samples were scanned at an excitation wavelength of $515 \mathrm{~nm}$ and the emission collected at the wavelength between 550 - $605 \mathrm{~nm}$ (excitation and emission slit widths were set at $5 \mathrm{~nm}$ ). All experiments were conducted at $22^{\circ} \mathrm{C}$. The EtBr emission intensity $f$, was plotted against the lipid to DNA charge ratio $R$, and the results were fitted either linearly or parabolically within a 95\% confidence level. The interaction of MTC was shown to be a special case of cooperative interaction and was simulated by Eq.1:

$$
f=f_{\min }+\frac{f_{\max }-f_{\min }}{1+\left(\frac{R}{R_{1 / 2}}\right)^{n}}
$$

where $f_{\min }$ and $f_{\max }$ are the lowest and highest normalized fluorescence intensities, respectively, $R$, is the $+/$ - charge ratio, $R_{1 / 2}$ is the charge ratio at which $50 \%$ of plasmid DNA is neutralized or compacted by cationic lipid and the exponent $n$ denotes the steepness of the curve. Data were fitted by the method of non-linear least-squares using the Microsoft Excel Solver function, through minimization of the square residuals with 3 adjustable parameters $\left(f_{\min }, f_{\max }\right.$ and $\left.R_{1 / 2}\right)$ at $5 \%$ tolerance.

\subsection{Gel Retardation Assay}

$0.8 \%$ Agarose solution was prepared in $40 \mathrm{mM}$ TAE (Tris base, glacial acetic acid and EDTA) pH 7.4, followed by the addition of $10 \mu \mathrm{L} \mathrm{EtBr}\left(10 \mathrm{mg} \mathrm{mL}^{-1}\right)$. The lipoplexes were prepared by keeping the pDNA amount constant at $0.2 \mu \mathrm{g}$ while the amount of cationic lipid (0.6 $\mathrm{mM}$ ) was varied to produce lipid to pDNA charge ratios of $0.5,1,2,4,6$ and 8 . Naked pDNA $(0.2 \mu \mathrm{g})$ was used as a control in the first and last lanes. To each sample 1 $\mu \mathrm{L}$ of a $6 \mathrm{X}$ gel loading buffer $(0.25 \% \mathrm{w} / \mathrm{v}$ bromophenol blue, $0.25 \% \mathrm{w} / \mathrm{v}$ Xylene cyanol FF, $30 \% \mathrm{v} / \mathrm{v}$ glycerol in water) was added and the volume was brought to $11 \mu \mathrm{L}$ with $40 \mathrm{mM}$ TAE buffer $\mathrm{pH}$ 7.4. The samples were allowed to sit for 10 - 15 minutes before they were loaded onto the wells of the agarose gel. Afterwards, an appropriate amount of running buffer (TAE) was used to submerge the gel and the gel was subjected to an electrophoretic field of $90 \mathrm{~V}$ for $35 \mathrm{~min}$. The results of the gel electrophoresis were assessed using a Bio-Rad Mini Transilluminator.

\subsection{Langmuir Monolayer Studies}

Cationic lipid monolayers were studied at the air/water 
interface using the Langmuir film balance technique as described elsewhere [16]. Compression isotherms of the cationic lipids were obtained using a Langmuir film balance (model KSV 1000, KSV instruments LTD, Finland) equipped with a Wilhelmy plate for measuring the surface pressure. The Teflon microtrough $\left(24,225.0 \mathrm{~mm}^{2}\right)$ is equipped with two barriers that allow for symmetric compression. Each run was followed by a thorough wash of both trough and barriers with ethanol and a final rinse with distilled water. The Wilhelmy plate was heated over a blue flame for about 30 seconds before each run. In a typical experiment, $15 \mu \mathrm{L}(30.0 \mathrm{nmol})$ of cationic lipid (2 $\mathrm{mM}$ dissolved in chloroform) was spread onto the subphase $(40 \mathrm{mM}$ Tris buffer $\mathrm{pH} 7.2)$ maintained at $22^{\circ} \mathrm{C}$, with a Hamilton $\AA$ micro syringe and allowed to sit for 15 min before the start of each run. The barriers were compressed at a constant speed of $10 \mathrm{~mm} \cdot \mathrm{min}^{-1}$. All experiments were conducted at a temperature of $22^{\circ} \mathrm{C}$, while each run was repeated at least three times for reproducibility. Independent and dependent variables collected by the instrument were imported into an Excel spreadsheet and the compressibility modulus, $K$, was calculated from the first derivative of the monolayer surface pressuretrough Area isotherms using Eq.2:

$$
K=-A\left(\frac{\partial \Pi}{\partial \mathrm{A}}\right)_{T}
$$

Equilibrium parameters at the onset of monolayer collapse were determined at the peak point of the $K$ - $\Pi$ isotherm.

\section{6. $\mathrm{p} K_{\mathrm{a}}$ Studies}

Buffer solutions $(2 \mathrm{~mL})$ made from $40 \mathrm{mM}$ Tris and $40 \mathrm{mM}$ MES having a $\mathrm{pH}$ from 1.2 to 13.2 were transferred into plastic cuvettes together with $0.1 \mathrm{~mL}$ of lipid dispersions $(0.6 \mathrm{mM}$ for cationic lipid $(\mathrm{CL})$ alone and 2 $\mathrm{mM}$ for $\mathrm{CL} / \mathrm{DOPC} / \mathrm{Chol}$ 0.2/0.9/0.9 molar ratio) and 6 $\mu \mathrm{L}$ of TNS $(0.1 \mathrm{mM})$ for $\mathrm{CL}$ alone and $20 \mu \mathrm{L}$ TNS $(0.1$ $\mathrm{mM}$ ) for CL/DOPC/Chol 0.2/0.9/0.9 mol $/ \mathrm{mol} / \mathrm{mol}$ ). The lipid to probe molar ratio was kept constant at $100: 1$. The static fluorescence intensity of these samples was registered at an excitation wavelength of $321 \mathrm{~nm}$ (slit width $5 \mathrm{~nm}$ ) and an emission wavelength of $445 \mathrm{~nm}$ (slit width $5 \mathrm{~nm}$ ) on a Cary Eclipse fluorescence spectrophotometer at $25^{\circ} \mathrm{C}$. The emission intensity of TNS was plotted against the $\mathrm{pH}$ and the results were fitted using a modified version of the Henderson-Hasselbalch (Equation 3), using the

$$
f=f_{\min }+\frac{f_{\max }-f_{\min }}{1+10^{c \cdot(\mathrm{pH}-p K a)}}
$$

Microsoft Excel Solver through minimization of the sum of the squared residuals with four adjustable parameters at a $5 \%$ tolerance level [17]. The parameter, $f$ is the calculated TNS fluorescence, $f_{\max }$ and $f_{\min }$ are the maximum and minimum fluorescence values of TNS and $c$ is a constant that adjusts the slope of the curve.

\subsection{Particle Size and Electrophoretic Mobility Studies}

A Malvern Zetasizer Nano Series instrument was used to determine the size and zeta potential of the pure cholesterol derivatives and corresponding lipoplexes at + charge ratios of $1: 1,2: 1$ and $4: 1$. Experiments were performed in both filtered Tris buffer (using $0.2 \mu \mathrm{m}$ membrane filter) and SFM at $22^{\circ} \mathrm{C}$. Lipoplexes were prepared by adding pDNA into $200 \mu \mathrm{L}$ of $0.6 \mathrm{mM}$ lipid dispersion to produce the desired lipid to pDNA charge ratios and then diluted to $1.5 \mathrm{~mL}$ with Tris buffer (40 $\mathrm{mM}, \mathrm{pH}$ 7.2) or SFM [17].

\section{RESULTS AND DISCUSSION}

\subsection{In Vitro Transfection and Cytotoxicity Studies}

Regardless of charge ratio, the MAC mediated highest transfection activity while the quaternary ammonium salt, MTC, exhibited the lowest potency among its peers (Figure 1(a)). The invariable $\beta$-gal expression levels by MAC could be due to decreased cell viability with increasing charge ratio. Impressively, unlike DC-Chol which is transfection incompetent in the absence of DOPE, the MDC and EDC that bear methyl and ethyl substitution at the carbamoyl nitrogen, respectively, mediated significant transfection activity proportional to charge ratio. More specifically, at $+/-$ charge ratio of 1 , the activity mediated by the cationic lipids decreased with polar head methyl substitution, while at $+/$ - charge ratio of 2 and 4 the transfection activity mediated by MMC, MDC and EDC was essentially indistinguishable. MDC exhibited the lowest toxicity maintaining greater than $70 \%$ cell viability, whereas MMC was quite cytotoxic at all charge ratios (Figure 1(b)).

\section{2. $\mathrm{p} K_{\mathrm{a}}$ Studies}

The $\mathrm{p} K_{a}$ of cationic lipids is conventionally determined in mixed lipid vesicles using the membrane potential indicator TNS [17-21]. In this investigation, an attempt was made to determine the apparent $\mathrm{p} K_{a}$ of cationic lipids from pure assemblies in the absence of any co-lipids. As shown in Table 1, the $\mathrm{p} K_{a}$ of the primary amine derivative MAC is slightly lower than that of the secondary amine derivative MMC. Further methyl substitution on the amine polar head drastically decreases the $\mathrm{p} K_{a}$ by one unit (MDC), while the apparent $\mathrm{p} K_{a}$ of the ethyl carbamoyl tertiary amine derivative EDC, is even lower reaching 


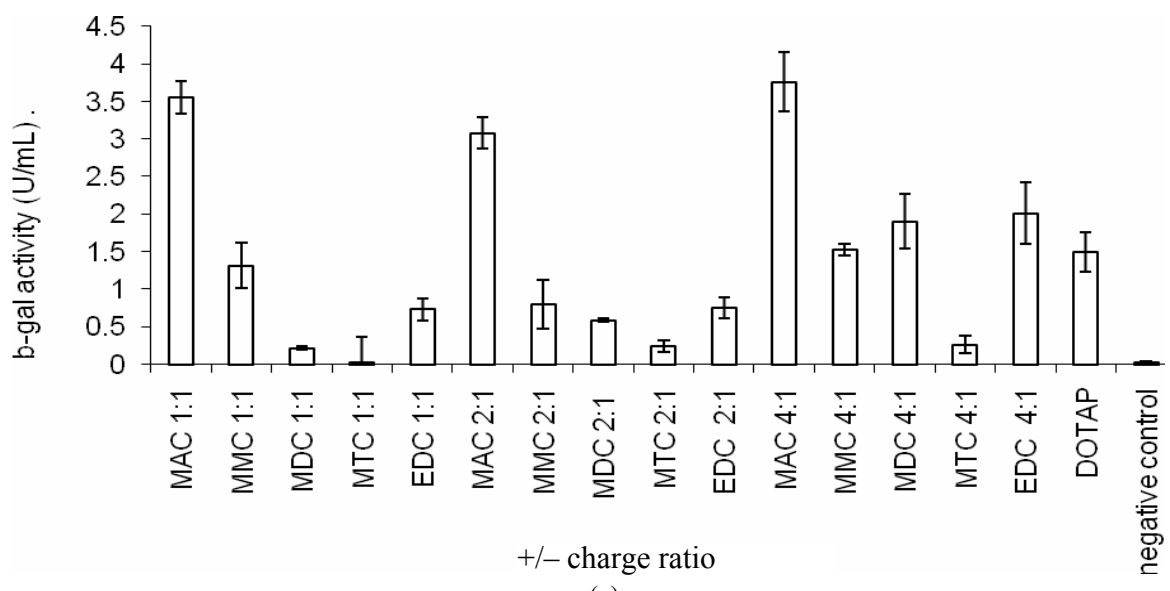

(a)

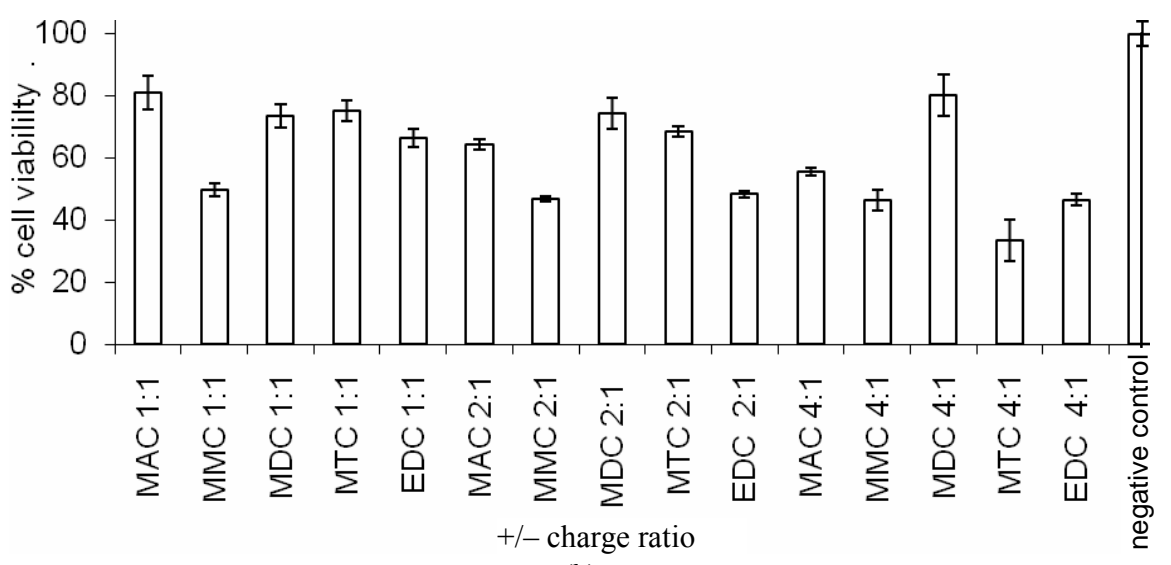

(b)

Figure 1. (a) Transfection activities and (b) Cytotoxicity studies of MAC, MMC, MDC, MTC and EDC at different $+/-$ charge ratios in mouse melanoma cells (B16F0). Results are the average of three different experiments. In the control experiment, plasmid DNA was added to the cells without cationic lipids.

Table 1. Apparent $\mathrm{pKa}$ of cationic lipids determined at $25^{\circ} \mathrm{C}$ in pure cationic assemblies and in the presence of DOPC and cholesterol $(\mathrm{CH})$ at a molar ratio of $2: 9: 9$.

\begin{tabular}{cccc}
\hline Composition & $\mathrm{p} K_{a}$ & Composition & $\mathrm{p} K_{a}$ \\
\hline MAC & $7.19 \pm 0.06$ & $\mathrm{MAC} / \mathrm{DOPC} / \mathrm{CH}$ & $8.83 \pm 0.055$ \\
MMC & $7.24 \pm 0.06$ & $\mathrm{MMC} / \mathrm{DOPC} / \mathrm{CH}$ & $8.82 \pm 0.16$ \\
MDC & $6.17 \pm 0.09$ & $\mathrm{MDC} / \mathrm{DOPC} / \mathrm{CH}$ & $7.54 \pm 0.07$ \\
EDC & $6.04 \pm 0.03$ & $\mathrm{EDC} / \mathrm{DOPC} / \mathrm{CH}$ & $7.37 \pm 0.14$ \\
DC & $6.76 \pm 0.075$ & - & - \\
\hline
\end{tabular}

the value of 6.04. This trend, $\mathrm{MMC}>\mathrm{MAC}>\mathrm{MDC}>$ EDC can be explained by the lipid hydration that precedes the inductive effect $[22,23]$. Generally, the amine basicity is increased with methyl substitution due to the electron donation from the methyl groups. However, in aqueous solution, the increased electron density and basicity of the methyl substituted nitrogen is compromised by the low solvation energy of the increasingly hydrophobic substituted nitrogen. Interestingly, the $\mathrm{p} K_{a}$ of the $\mathrm{DC}$ is much higher than that of MDC (6.76 versus 6.17) but significantly lower than the structural isomer MMC.
Thus, moving the methyl group from the amine head to the carbamoyl group increases the $\mathrm{p} K_{a}$ by 0.5 units and converts an ineffectual lipid into a transfection potent one.

As with the pure assemblies, mixed assemblies containing primary and secondary amine derivatives were more basic by 1.3 and $1.5 \mathrm{pH}$ units than those containing the tertiary amine derivatives MDC and EDC, respectively (Figure 2 and Table 1). Furthermore, due to the increased molecular separation, the $\mathrm{p} K_{a}$ of all cationic lipids in mixed vesicles composed of $90 \%$ DOPC and 

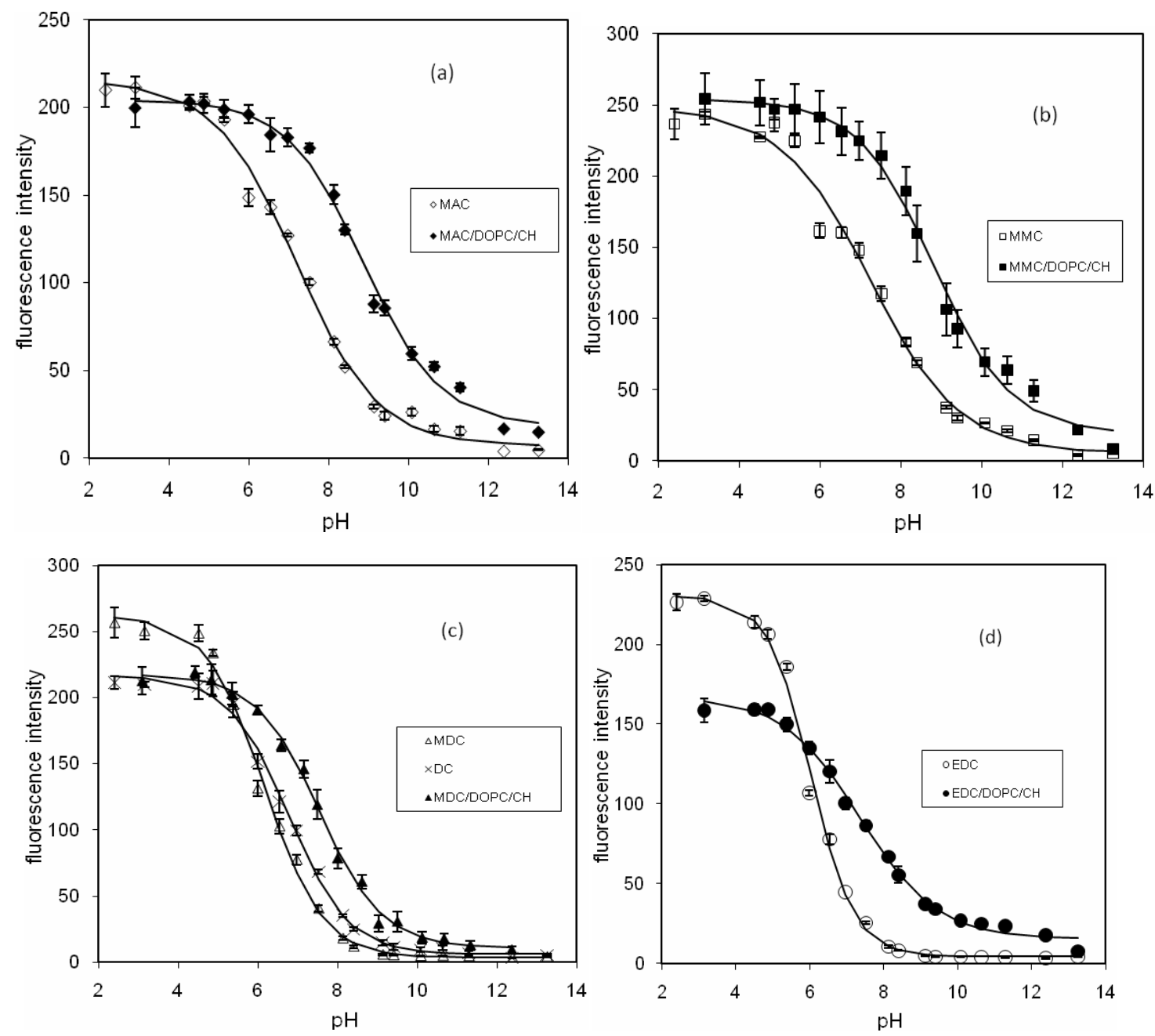

Figure 2. Fluorescence intensity of TNS as a function of bulk pH in pure and mixed cationic assemblies at $25^{\circ} \mathrm{C}$. Results are the average of three independent experiments with the error bars representing standard uncertainties.

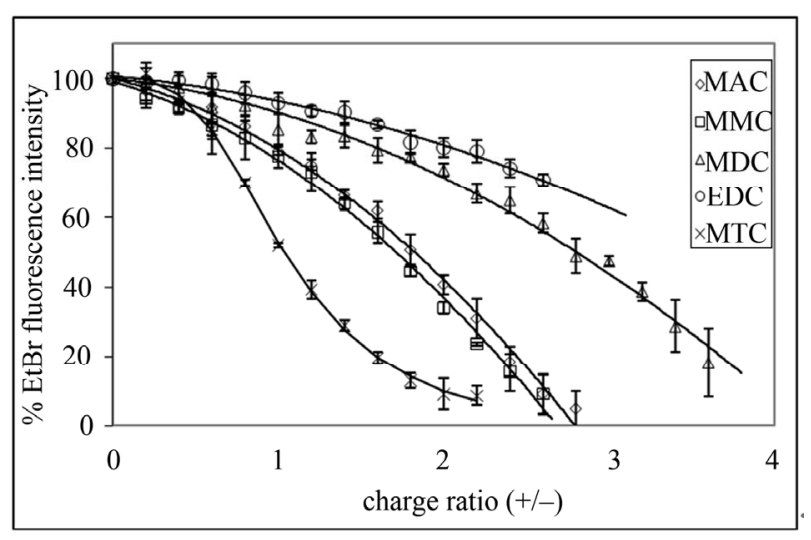

(a)

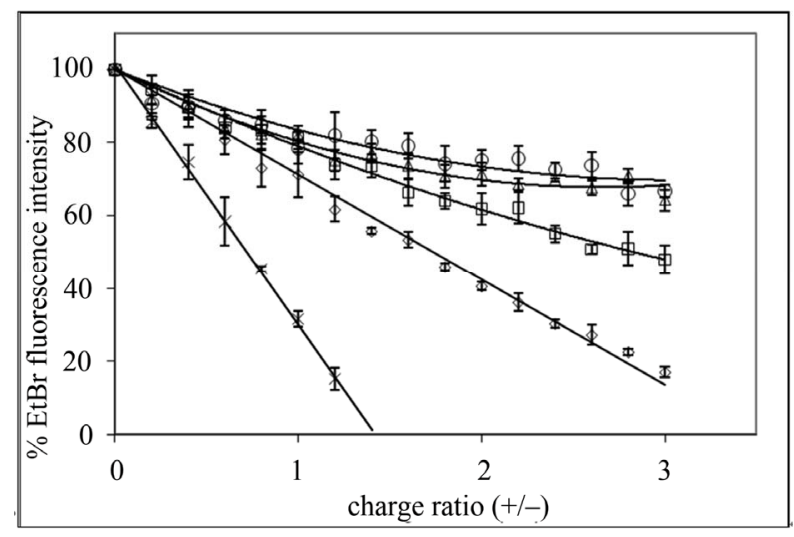

(b)

Figure 3. EtBr displacement assay at $22^{\circ} \mathrm{C}$ (a) in $40 \mathrm{mM}$ Tris buffer $\mathrm{pH} 7.2$; (b) in serum free media (SFM) of physiological ionic strength. Symbols are the average of 3 different experiments while solid lines represent data fitted by linear equations and parabolas (top panel). The interaction of MTC with plasmid DNA in $40 \mathrm{mM}$ Tris pH 7.2 (top panel) was simulated by Eq.2, as described in Materials and Methods. 


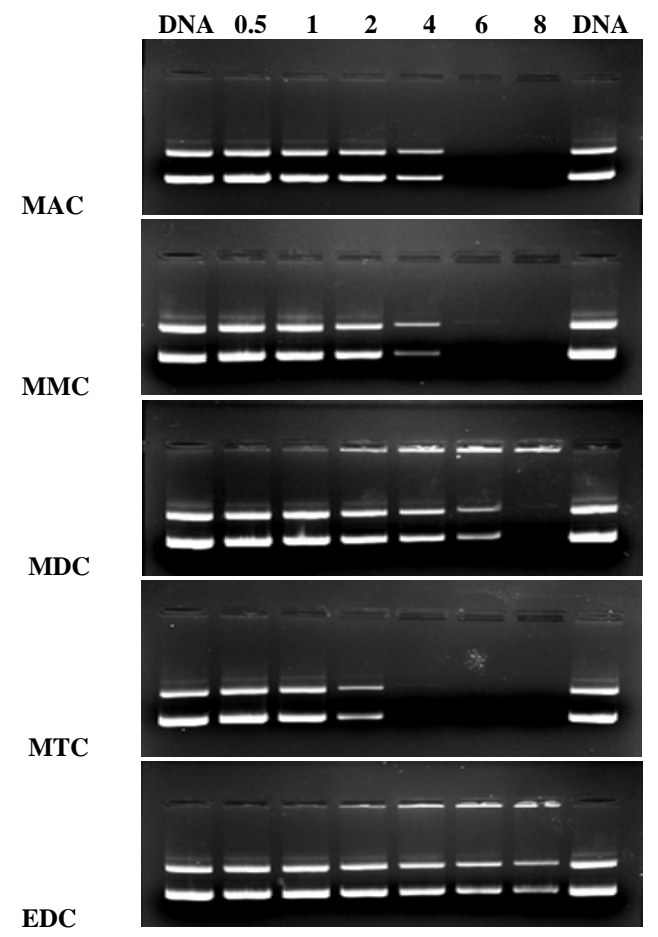

Figure 4. Representative agarose gel retardation studies in 40 $\mathrm{mM}$ Tris buffer $\mathrm{pH} 7.2$ of MAC, MMC, MDC, MTC and EDC at different $+/$ - charge ratios (no lipid, $0.5,1,2,4,6,8$, no lipid).

cholesterol increased by 1.3 to 1.6 units. However, what is really interesting is the fact that $90 \%$ ionization takes place within $\pm 2 \mathrm{pH}$ units from the $\mathrm{p} K_{a}$ value and not 1 unit as predicted by the Henderson-Hasselbalch equation. This expansion of the buffering region of cationic cholesterol assemblies was not observed with double-chained monovalent cationic lipids (results not shown) and it definitely extends the range of $\mathrm{pH}$ at which cationic lipidDNA interaction occurs.

Interestingly, the transfection efficiency decreased with the increase in the methylation on the terminal nitrogen while it surprisingly increased with the increase in alkyl chain of the carbamoyl nitrogen. This trend reveals that higher ionization of a cationic lipid is not always correlated with a higher transfection activity.

\subsection{Monolayer studies}

As shown in Table 2, the trend in the mean molecular areas $(\mathrm{MmA})$ of cationic lipids at the onset of collapse pressure is $\mathrm{MTC}>\mathrm{MMC}>\mathrm{MAC}>\mathrm{MDC}>\mathrm{EDC}$. Looking at the MDC and EDC derivatives, the mean surface area decreased from $35.7 \AA^{2}$ molecule ${ }^{-1}$ for MDC to 33.7 $\AA^{2}$ molecule ${ }^{-1}$ for EDC. Tighter packing of EDC as compared to MDC molecules is due to the increased van der Waals forces and the lower $\mathrm{p} K_{a}$, both a consequence of the increased hydrophobicity of the molecule which is also reflected in lower monolayer collapse pressure and
Table 2. Monolayer properties determined at the onset of monolayer collapse with $40 \mathrm{mM}$ Tris buffer $\mathrm{pH} 7.2$ as the subphase at $22^{\circ} \mathrm{C}$. Standard uncertainties were calculated from three to five independent experiments. The \% ionization of cationic lipids in the monolayers were calculated from the measured pKa values included in Table $\mathbf{1}$.

\begin{tabular}{ccccc}
\hline $\begin{array}{c}\text { Cationic } \\
\text { lipid }\end{array}$ & $\operatorname{MmA}\left(\AA^{2}\right)$ & $\Pi\left(\mathrm{mN} \mathrm{m}^{-1}\right)$ & $K\left(\mathrm{mN} \mathrm{m}^{-1}\right)$ & $\begin{array}{c}\text { \% ioniza- } \\
\text { tion }\end{array}$ \\
\hline MAC & $36.6 \pm 0.3$ & $42.5 \pm 2.4$ & $212 \pm 21$ & $49.3 \pm 3.4$ \\
MMC & $37.6 \pm 1$ & $41.9 \pm 0.4$ & $233 \pm 48$ & $52.4 \pm 3.4$ \\
MDC & $35.7 \pm 1.1$ & $42.6 \pm 1.7$ & $151 \pm 12$ & $8.60 \pm 2$ \\
EDC & $33.7 \pm 1$ & $37.3 \pm 2.1$ & $126 \pm 10$ & $6.50 \pm 0.4$ \\
MTC & $44.6 \pm 0.4$ & $32.0 \pm 0.9$ & $123 \pm 11$ & 100 \\
\hline
\end{tabular}

Table 3. (+/- charge ratio at which $50 \%$ of plasmid DNA is compacted in $40 \mathrm{mM}$ Tris buffer $\mathrm{pH} 7.2$ and in Serum Free Media (SFM) at $22^{\circ} \mathrm{C}$.

\begin{tabular}{ccc}
\hline Cationic lipid & $40 \mathrm{mM}$ Tris buffer & SFM \\
\hline MAC & 1.8 & 1.7 \\
MMC & 1.7 & 2.7 \\
MDC & 2.8 & - \\
EDC & 3.5 & - \\
MTC & 1.1 & 0.7 \\
\hline
\end{tabular}

magnitude of the compressibility modulus, $K$.

The trend in the MmA of cationic lipids as a function of amino group methyl substitution (MTC $>$ MMC $>$ MAC $>$ MDC) verifies that cationic lipid molecular dimensions are directly proportional to the $\mathrm{p} K_{a}$ and degree of ionization in Tris buffer $\mathrm{pH}$ 7.2. Thus, although MDC is a bulkier tertiary amine, the increased ionization of the primary amine MAC at $\mathrm{pH} 7.2$ (49\% versus 9\%; Table 2), encourages greater hydration and repulsion among the aligned molecules in the interface, thus effectively increasing its molecular dimensions as determined just before the monolayer collapse.

\subsection{EtBr Displacement and Exclusion Studies}

To better understand the transfection activity profile of the cationic lipids, their ability to bind and compact pDNA was assessed using the EtBr displacement assay. The cationic lipids displaced EtBr from pDNA in $40 \mathrm{mM}$ Tris $\mathrm{pH} 7.2$ in the following order: $\mathrm{MTC}>\mathrm{MMC}>$ MAC $>$ MDC $>$ EDC (Figure 3(a)). Thus, the more basic the lipid and the more expanded the molecular dimensions, the more efficient is its interaction with plasmid DNA. This trend was also observed with a gel retardation assay, although none of the lipids was able to completely retard the pDNA at the exact ratio as determined in the EtBr displacement assay (Figure 4). In the high ionic strength serum free media (SFM), the interaction cooperativity observed in $40 \mathrm{mM}$ Tris was lost and the order of interaction was changed to MTC $>$ MAC $>$ 
MMC. MDC and EDC failed to significantly condense the plasmid DNA (Figure 3(b)). Most importantly, the charge ratio at which $50 \%$ of $\mathrm{EtBr}$ is displaced from pDNA decreased from 1.1 in $40 \mathrm{mM}$ Tris to 0.7 for MTC, remained the same around 1.7 to 1.8 for the MAC and increased from 1.7 to 2.7 for MMC (Table 3). Evidently, the increased ionic strength of the media did not adversely affect the electrostatic interaction of the more hydrophilic quaternary ammonium salt MTC and primary amine derivative MAC, but it seriously reduced the reactivity of the more lipophilic secondary and tertiary amine derivatives MMC and MDC and EDC, respectively, due to reduced hydration.

\subsection{Particle Size and Electrophoretic Mobility Studies}

Cationic lipid dispersions in the absence of pDNA were in general below $200 \mathrm{~nm}$ in $40 \mathrm{mM}$ Tris buffer $\mathrm{pH}$ 7.2. The smallest particle diameter was exhibited by the quaternary ammonium derivative MTC presumably due to increased ionization and polar head expansion. Owing to reduced hydration, the particle size of cationic lipid dispersions and corresponding zeta potential increased and decreased, respectively, in the high ionic strength SFM (Table 4). The lipoplexes exhibited a very different, but predictable, zeta potential and particle size distribution (Table 5). Lipoplex particles were slightly bigger than the size of cationic lipid dispersions in the absence of pDNA in $40 \mathrm{mM}$ Tris and SFM, until the point of charge neutrality where a big jump in the lipoplex size was observed. Specifically, as previously determined by the $\mathrm{EtBr}$ displacement assay, complete charge neutralization occurs at $+/-$ charge ratio of 2 and 4 for MTC and MAC and MMC, respectively. A drastic increase in lipo-

Table 4. Hydrodynamic characterization of lipid dispersions (in the absence of DNA) carried out in $40 \mathrm{mM}$ Tris buffer $\mathrm{pH} 7.4$ and serum free media $(\mathrm{SFM})$ at $22^{\circ} \mathrm{C}$. Standard uncertainties were calculated from the average values measured from three separate experiments.

\begin{tabular}{ccccccc}
\hline Composition & \multicolumn{2}{l}{ Hydrodynamic Diameter $(\mathrm{nm})$} & \multicolumn{2}{c}{ PDI } & \multicolumn{2}{c}{ Zeta Potential (mV) } \\
\hline MAC & $\underline{40 \mathrm{mM} \text { Tris }}$ & $\underline{\text { SFM }}$ & $\underline{40 \mathrm{mM} \text { Tris }}$ & $\underline{\text { SFM }}$ & $\underline{40 \text { Mm Tris }}$ & $\underline{\text { SFM }}$ \\
MMC & $160 \pm 6$ & $258 \pm 78$ & $0.26 \pm 0.02$ & $0.15 \pm 0.01$ & $+53 \pm 3$ & $+19.5 \pm 1$ \\
MDC & $113 \pm 7$ & $160 \pm 9$ & $0.24 \pm 0.01$ & $0.26 \pm 0.02$ & $+55 \pm 1$ & $+24 \pm 2$ \\
EDC & $169 \pm 14$ & $183 \pm 11$ & $0.39 \pm 0.07$ & $0.36 \pm 0.04$ & $+45 \pm 1.5$ & $+21 \pm 3$ \\
MTC & $203 \pm 26$ & $302 \pm 83$ & $0.45 \pm 0.03$ & $0.40 \pm 0.01$ & $+45 \pm 2.6$ & $+22 \pm 2$ \\
\hline
\end{tabular}

Table 5. Particle size and zeta potential of lipoplexes at various charge ratios in Tris $40 \mathrm{mM}$ buffer $\mathrm{pH} 7.2$ and in Serum Free Medium (SFM) at $22^{\circ} \mathrm{C}$. Standard uncertainties were calculated from the average values measured from three independent experiments.

\begin{tabular}{|c|c|c|c|c|c|c|c|}
\hline \multirow[t]{2}{*}{ Cationic lipid } & \multirow[t]{2}{*}{$\begin{array}{c}+/- \text { charge } \\
\text { ratio }\end{array}$} & \multicolumn{2}{|c|}{ Hydrodynamic Diameter (nm) } & \multicolumn{2}{|c|}{ Polydispersity index } & \multicolumn{2}{|c|}{ Zeta Potential (mV) } \\
\hline & & $40 \mathrm{mM}$ Tris & $\underline{\text { SFM }}$ & $40 \mathrm{mM}$ Tris & $\underline{\mathrm{SFM}}$ & $\underline{40 \mathrm{mM} \text { Tris }}$ & $\underline{\mathrm{SFM}}$ \\
\hline MAC & $1 / 1$ & $204 \pm 4$ & $199 \pm 7$ & $0.26 \pm 0.01$ & $0.20 \pm 0.01$ & $-52 \pm 2.3$ & $-27 \pm 3$ \\
\hline MAC & $2 / 1$ & $328 \pm 40$ & $247 \pm 14$ & $0.30 \pm 0.03$ & $0.22 \pm 0.01$ & $-51 \pm 1.5$ & $-31 \pm 3$ \\
\hline MAC & $4 / 1$ & $1173 \pm 714$ & $731 \pm 266$ & $0.71 \pm 0.4$ & $0.34 \pm 0.1$ & $-6.35 \pm 31.3$ & $-33 \pm 4$ \\
\hline MMC & $1 / 1$ & $200 \pm 59$ & $250 \pm 25$ & $0.25 \pm 0.04$ & $0.26 \pm 0.01$ & $-50 \pm 2.6$ & $-29 \pm 2$ \\
\hline MMC & $2 / 1$ & $174 \pm 32$ & $273 \pm 14$ & $0.18 \pm 0.07$ & $0.25 \pm 0.02$ & $-49 \pm 1.5$ & $-31 \pm 3$ \\
\hline $\mathrm{MMC}$ & $4 / 1$ & $1137 \pm 68$ & $658 \pm 166$ & $0.53 \pm 0.04$ & $0.32 \pm 0.16$ & $+36 \pm 4$ & $-35 \pm 1.3$ \\
\hline $\mathrm{MDC}$ & $1 / 1$ & $229 \pm 23$ & $260 \pm 25$ & $0.28 \pm 0.01$ & $0.26 \pm 0.02$ & $-55 \pm 2$ & $-30 \pm 2.3$ \\
\hline MDC & $2 / 1$ & $236 \pm 26$ & $304 \pm 31$ & $0.31 \pm 0.05$ & $0.32 \pm 0.08$ & $-55 \pm 2.6$ & $-31 \pm 2$ \\
\hline $\mathrm{MDC}$ & $4 / 1$ & $411 \pm 26$ & $383 \pm 35$ & $0.27 \pm 0.03$ & $0.28 \pm 0.07$ & $-52 \pm 0.4$ & $-31 \pm 2$ \\
\hline EDC & $1 / 1$ & $454 \pm 31$ & $418 \pm 112$ & $0.19 \pm 0.03$ & $0.26 \pm 0.09$ & $-61 \pm 2.6$ & $-29 \pm 2$ \\
\hline EDC & $2 / 1$ & $323 \pm 78$ & $448 \pm 149$ & $0.26 \pm 0.03$ & $0.20 \pm 0.05$ & $-60 \pm 2.6$ & $-31 \pm 0.2$ \\
\hline EDC & $4 / 1$ & $421 \pm 172$ & $484 \pm 116$ & $0.20 \pm 0.08$ & $0.29 \pm 0.01$ & $-59 \pm 2$ & $-33 \pm 2$ \\
\hline MTC & $1 / 1$ & $270 \pm 97$ & $737 \pm 437$ & $0.37 \pm 0.1$ & $0.54 \pm 0.16$ & $-38 \pm 0.6$ & $-25 \pm 2$ \\
\hline MTC & $2 / 1$ & $1350 \pm 1077$ & $3782 \pm 925$ & $0.70 \pm 0.2$ & $0.62 \pm 0.15$ & $-30 \pm 11$ & $-18 \pm 6.5$ \\
\hline MTC & $4 / 1$ & $172 \pm 13$ & $475 \pm 236$ & $0.33 \pm 0.05$ & $0.41 \pm 0.06$ & $+39 \pm 1$ & $+26 \pm 1$ \\
\hline
\end{tabular}


plex particle size was observed close to these charge ratios (Table 5). Charge neutralization in lipoplexes composed of these cationic lipids was verified in $40 \mathrm{mM}$ Tris $\mathrm{pH} 7.2$, where the zeta potential reverses sign and becomes positive or it is very close to zero as the charge ratio increases from $1: 1$ to $2: 1$ and $4: 1$.

In summary, it was found that increased hydration of cholesterol-based cationic lipids correlates with increased ionization, increased polar head group dimensions due to higher repulsive forces among the lipids and greater interaction with plasmid DNA, as shown by EtBr displacement and exclusion assays. Thus, hydration was found to be the primary factor controlling ionization of cationic lipids and their interaction with DNA. Factors affecting the hydration of the cationic lipids, such as increased ionic strength, were shown to adversely affect primarily the ionization and DNA interaction of the more hydrophobic tertiary (MDC, EDC) and secondary (MMC) amine derivatives. Furthermore, ionization and $\mathrm{p} K_{a}$ of the cholesterol-based cationic lipids increased tremendously by 1.3 to $1.5 \mathrm{pH}$ units in the presence of other lipids due to increased spacing, improved hydration and reduced electronic overlap. No correlation was found between the $\mathrm{p} K_{a}$ of cationic assemblies and the transfection activity. Also, the similarity in lipoplex particle size and zeta potential precludes predicting a cationic lipid trend in mediating transfection activity. However, comparison of this work with our published report on secondary carbamate isomers AC, MC, DC and TC [14] substantiates the following: Firstly, methylating or ethylating the carbamoyl nitrogen of DC decreases the $\mathrm{p} K_{a}$ of cationic assemblies and their interaction with plasmid DNA, but it substantially increases their transfection activity in the absence of the helper lipid DOPE. Secondly, the transfection activity of the tertiary carbamate analog MMC is significantly lower than that of the secondary carbamate MC, presumably due to toxicity issue. Thirdly, the transfection activity of the primary amine derivatives, $\mathrm{AC}$ and MAC, was highest, while the quaternary ammonium derivatives, TC and MTC were essentially transfection incompetent despite their highly efficient interaction with plasmid DNA.

\section{CONCLUSIONS}

Our success of measuring the apparent $\mathrm{p} K_{a}$ of pure cationic assemblies and demonstrating that membrane ionization in pure cationic assemblies is much lower than that in mixed membranes was followed by the unfortunate realization that transfection activity is not correlated with the $\mathrm{p} K_{a}$ of basic cationic lipids. The appropriate test to build structure-activity relationships is still to be discovered, but as our studies indicated, the key lies in the three analogs MMA, DC and MDC which their physico- chemical properties and their transfection activities differ drastically from each other. Rather a delicate balance between the hydrophilicity and hydrophobicity of these cationic lipids must be controlling their transfection potency.

\section{REFERENCES}

[1] Gao, X.A. and Huang, L. (1991) A novel cationic liposome reagent for efficient transfection of mammalian cells. Biochemical and Biophysical Research Communications, 179, 280-285. doi:10.1016/0006-291X(91)91366-K

[2] Middleton, P.G., Caplen, N.J., Gao, X., Huang, L., Gaya, H., Geddes, D.M. and Alton, E.W.F.W. (1994) Nasal application of the cationic liposome DC-Chol: DOPE does not alter ion transport, lung function or bacteria growth. European Respiratory Journal, 7, 442-445. doi:10.1183/09031936.94.07030442

[3] Blagbrough, I.S., Geall, A.J. and Neal, A.P. (2003) Polyamines and novel polyamine conjugates interact with DNA in ways that can be exploited in non-viral gene therapy. Biochemical Society Transactions, 31, 397-406. doi:10.1042/BST0310397

[4] Griesenbach, U., Kitson, C., Garcia, S.E., Farley, R., Singh, C., Somerton, L., Painter, H., Smith, R.L., Gill, D. R., Hyde, S.C., Chow, Y.-H., Hu, J., Gray, M., Edbrooke, M., Ogilvie, V., MacGregor, G., Scheule, R.K., Cheng, S.H., Caplen, N.J. and Alton, E.W.F.W (2006) Inefficient cationic lipid-mediated siRNA and antisense oligonucleotide transfer to airway epithelial cells in vivo. Respiratory Research, 7, 1-15.

[5] Vigneron, J.-P., Oudrhiri, N., Fauquet, M., Vergely, L., Bradley, J.-C., Basseville, M., Lehn, P. and Lehn, J.-M. (1996) Guanidinium-cholesterol cationic lipids: Efficient vectors for the transfection of eukaryotic cells. Proceedings of the National Academy of Sciences of the United States of America, 93, 9682-9686.

doi:10.1073/pnas.93.18.9682

[6] Fang, N., Wang, J., Mao, H.-Q., Leong, K.W. and Chan, V. (2003) BHEM-Chol/DOPE liposome induced perturbation of phospholipid bilayer. Colloids and Surfaces $B$ : Biointerfaces, 29, 233-245. doi:10.1016/S0927-7765(02)00207-2

[7] Ghosh, Y.K, Visweswariah, S.S. and Bhattacharya, S. (2000) Nature of linkage between the cationic head group and cholesterol skeleton controls gene transfection efficiency. Federation of European Biochemical Societies Letters, 473, 341-344. doi:10.1016/S0014-5793(00)01558-1

[8] Bajaj, A., Mishra, S.K., Kondaiah, P. and Bhattacharya, S. (2008) Effect of the headgroup variation on the gene transfer properties of cholesterol based cationic lipids possessing ether linkage. Biochimica et Biophysica Acta: Biomembranes, 1778, 1222-1236. doi:10.1016/j.bbamem.2007.12.010

[9] Esposito, C., Generosi, J., Mossab, G., Masotti, A. and Castellano, A.C. (2006) The analysis of serum effects on structure, size and toxicity of DDAB-DOPE and DCChol-DOPE lipoplexes contributes to explain their different transfection efficiency. Colloid Surface B Biointer- 
faces, 53, 187-192.

[10] Koltover, I., Salditt, T. and Safinya, C.R. (1999) Phase diagram, stability, and overcharging of lamellar cationic lipid-DNA self-assembled complexes. Biophysical Journal, 77, 915-924. doi:10.1016/S0006-3495(99)76942-0

[11] Felgner, P.L., Gadek, T.R., Holm, M., Roman, R., Chan, W., Wenz, M., Northorp, J.P., Ringold, G.M. and Danielsen, M. (1987) Lipofection: A highly efficient lipidmediated DNA transfection procedure. Proceedings of the National Academy of Sciences of the United States of America, 84, 7413-7417. doi:10.1073/pnas.84.21.7413

[12] Israelachvili, J.N., Marcelja, S. and Horn, R.G. (1980) Physical principles of membrane organization. Quarterly reviews of Biophysics, 13, 121-200. doi:10.1017/S0033583500001645

[13] Gruner, S.M., Cullis, P.R., Hope, M.J. and Tilcock, P.S. (1985) Lipid polymorphism: The molecular basis of nonbilayer phases. Annual Review of Biophysics and Biophysical Chemistry, 14, 211. doi:10.1146/annurev.bb.14.060185.001235

[14] Kearns, M., Donkor, A.M. and Savva, M. (2008) Structure-Transfection activity studies of novel cationic cholesterol-based amphiphiles. Molecular Pharmaceutics, 5, 128-139. doi:10.1021/mp700131c

[15] Sambrook, J., Fritsch, E.F. and Maniatis, T. (1989) Molecular cloning: A laboratory manual. 2nd Edition, Cold Spring Harbor Laboratory Press, New York.

[16] Savva, M. and Acheampong, S. (2009) The interaction energies of cholesterol and 1,2-dioleoyl-phosphoetha- nolamine in spread mixed monolayers at the air-water interface. Journal of Physical Chemistry B, 113, 9811-9820. doi:10.1021/jp902748s

[17] Spelios, M. and Savva, M. (2008) Novel N,N'-1,3diaminopropyl-2-carbamoyl bivalent cationic lipids for gene delivery-synthesis, in vitro transfection activity, and physicochemical characterization. Federation of European Biochemical Societies Journal, 275, 148-162.

[18] Wang, J.L. and Edelman, G.M. (1971) Fluorescent probes for confromational states of proteins. Journal of Biological Chemistry, 246, 1185-1191.

[19] Bailey, A.L. and Cullis, P.R. (1994) Modulation of membrane fusion by asymmetric transbilayer distributions of amino lipids. Biochemistry, 33, 12573-12580. doi:10.1021/bi00208a007

[20] Asokan, A. and Cho, M.J. (2003) Cytosolic delivery of macromolecules II. Mechanistic studies with $\mathrm{pH}$-sensitive morpholine lipids. Biochimica et Biophysica Acta: Biomembranes, 161, 151-160.

[21] Heyes, J., Palmer L., Bremner, K. and MacLachlan, I. (2005) Cationic lipid saturation influences intracellular delivery of encapsulated nucleic acids. Journal of Controlled Release, 107, 276-287. doi:10.1016/i.jconrel.2005.06.014

[22] Marchington, A.F., Moore, S.C.R. and Richards, W.G. (1979) The inductive effect in molecules and ions. Journal of the American Chemical Society, 101, 5529-5532. doi:10.1021/ja00513a012

[23] Miessler, G.L. and Tarr, D.A. (2003) Inorganic Chemistry, Prentice Hall, New Jersey. 